\title{
First Announcement of the Fanconi Anemia International Registry
}

\author{
Arleen D. Auerbach ${ }^{1}$ and Traute M. Schroeder ${ }^{2}$ \\ ${ }^{1}$ Laboratory for Investigative Dermatology, The Rockefeller University, 1230 York Avenue, New York, New York 10021, USA \\ ${ }^{2}$ Institute of Human Genetics, University of Heidelberg, Im Neuenheimer Feld 328, D-6900 Heidelberg, Federal Republic of Germany
}

We call upon our colleagues to cooperate with us in establishing and maintaining an International Registry of all known Fanconi anemia (FA) patients. The aim of this registry is to gather data in order to define the clinical and genetic hetero-

Offprint requests to: T. M. Schroeder (address see above) geneity in the disorder, to establish a means of exact differential diagnosis, and to study the incidence of malignancy in FA patients and family members.

We ask all of our colleagues in genetics and hematology to join us in this study. Correspondence from physicians and scientists who are aware of patients with FA is invited.

\section{Polymorphism of Properdin Factor B in Japanese. Description of a Rare Variant and Data of Association with HLA and C2}

\author{
K. Tokunaga, C. Araki, T. Juji, and K. Omoto
}

Hum Genet (1982) 60:42-45

The variant BF F0.8 referred in the Discussion, page 44, second paragraph, lines five and six, was found "in an African Negroid population", not "in French". [Davrinche C, Rivat C, Rivat-
Peran L, Cazes MH, Chaventre A. A new fast variant (BF*F08) of the $\mathrm{BF}$ polymorphism. $\mathrm{J}$ Immunogenet (in press).] We gratefully acknowledge the information by Dr. Christian Davrinche. 